A new dispute has arisen between epidemiologists and health physicists over the interpretation of data on the health effects of low levels of ionizing radiation, the subject of a recent report from the National Academy of Sciences (Nature 7 August p. 550).

This time the disagreement centres on whether current exposure limits to the radioactive gas radon and its decay products may present an unnecessarily high risk of lung cancer to the 7,000 uranium miners currently employed in the United States.

And the precise shape of the low-level dose-response curve has been given a new significance by growing concern about the possible health risk to the general public from radon-emitting building materials, since radon's precursor, radium-226, is a trace element contained in most rocks and soil.

In the light of epidemiological evidence on occupational exposures that has been accumulated since the current standards were set in 1971, the National Institute of Occupational Safety and Health (NIOSH) has suggested to the Department of Labor that permitted exposure limits for uranium miners should be significantly reduced.

However, the International Council for Radiological Protection (ICRP) argues that no change is needed. In a set of new recommendations currently being circulated to its members, the ICRP says that on the basis of dosimetric techniques applied to models of the lung, the current exposure limits appear to be adequate.

Mining companies - already facing a tight economic squeeze because of a virtual collapse in the international market for uranium ore - are using the ICRP's arguments to press the department not to reduce the limits. A move to reduce the limits could mean that mining companies would have to install expensive ventilation equipment.

Research in the 1950s and 1960s confirmed an abnormally high incidence of lung cancer among uranium miners. The cause was identified as radon and its alphaemitting decay products - known as radon daughters - which become attached to air particles and can lodge in miners' lungs. The Department of the Interior introduced in 1971 an exposure limit of 4 working level months (WLM) a year, with a ceiling airborne concentration not to exceed 1.0 WL. (One working level (WL) is defined as a radon daughter concentration in one litre of air resulting in the emission of $1.3 \times 10^{5}$ $\mathrm{MeV}$ of potential alpha energy).

Since then, evidence from epidemiological studies in Canada, Sweden, Czechoslovakia and the United States, suggests, according to a report put together by a NIOSH study group, that the full effects of radon exposure may have been underestimated, and that "there appears to be no margin of safety associated with the present standard".

The working group point out that triggering doses may be substantially lower than the cumulative doses associated with a particular incidence of lung cancer, since the radiation absorbed after the triggering dose may have been biologically redundant. In addition, the contribution of smoking to lung cancer among miners may have been overestimated in previous work. Some studies appear to show a higher rate of lung cancer among miners who do not smoke than among those who do - perhaps because cigarette smoking creates a thicker layer of mucus which may provide some protection against alpha emissions.

In submitting the report to the Department of Labor's Mine Safety and Health Administration (MSHA) Dr Anthony Robbins, Director of NIOSH, says that the apparent excess risk of lung cancer among those who might accumulate 120 WLM over a working lifetime perhaps twice previous estimates - was a cause for major public health concern.

"On the basis of the study group's report, we feel that the present MSHA standard of 4 WLM per year does not provide an adequate degree of protection for underground miners exposed to radiation when it is evaluated over their exposure lifetime,"' Dr Robbins says.

NIOSH officials met with MSHA at the beginning of this month, and agreed that there is enough scientific evidence to support a possible revision of the regulation.

The department has already been petitioned to reduce permitted exposure levels by Ralph Nader's Health Resources Group and the Oil Chemical and Atomic Workers, a labour union to which many of the uranium miners belong. The two organizations are demanding that the maximum allowed radiation be reduced from 4 to 0.7 WLM per year.

However, the department is being urged by the industry to take into account the ICRP regulations suggesting little need for change. The ICRP proposals, agreed in draft form at a meeting of the commission in Brighton, UK earlier this year, describe two different ways of estimating what might be considerd a safe exposure level.

Using epidemiological techniques based essentially on the same data as those analysed by the NIOSH working group, ICRP suggest that a safe limit would be between 2 and 10 WLM per year.

However, the ICRP also makes estimates based on a dosimetric analysis of the expected effect on the lung of a given amount of radiation, and in particular to that region of the lung particularly susceptible to alpha emission.
The latter approach, according to the ICRP, leads to a recommended exposure limit of 5-8 WLM per year based on a regular lung dose, or 9-14 WLM per year based on a mean lung dose. And given the variability in the epidemiological data, ICRP suggests that a figure of 5 WLM should be used as the basis for regulation adding that for uranium miners already exposed to additional gamma radiation, this limit would tend to be reduced by 20 per cent for radon daughters alone, bringing it in line with the current US standard.

Ironically this conculsion is somewhat in conflict with the judgement of the National Academy of Sciences' Committee on the Biological Effects of Ionizing Radiation (BEIR), which last month moved closer to ICRP's position that for a different type of low level radiation (that resulting from $\mathrm{X}$ rays and gamma rays) a linear doseresponse model may overstate the dangers.

In its comments on the dangers from alpha emission and other sources of highLET (linear energy transfer) radiation, however, the BEIR committee drew heavily on the epidemiological studies of uranium miners and others to conclude that "the application of the linear hypothesis is less likely to lead to overestimates of risk and may, in fact, lead to underestimates",

David Dickson

\section{High-altitude research}

\section{Reflated hopes}

A threat to halt the launching of large scientific balloons from two sites in Australia may yet be averted if a proposal to update equipment and share running costs is accepted by the five countries which regularly use them. The continuation of the facilities is particularly important for astronomers from Australia, the United States, Britain, Germany and Japan who want to send balloon-borne payloads to high altitudes to study X-ray and UV sources in the Southern Hemisphere near the Galactic Centre.

The Australian government has threatened to close the facilities at Mildura, Victoria and Alice Springs in the Northern Territory because it says that it is heavily subsidizing foreign astronomers whose governments do not pay an economic fee. The United States is the only country that currently contributes to running costs: it pays a third, Australia making up the remaining two thirds. Other users of the facility currently pay about $£ 10,000-11,000$ for a launch and nothing towards basic running costs. 
Britain, Germany and Japan have each been launching on average two to three balloons per year. Australia started searching for alternative funds four years ago when Britain was the main foreign user apart from the United States. An attempt then to get Britain to pay one third of the running costs, about $£ 50,000$, failed with Britain's Science Research Council pleading poverty.

The current threat to close the facilities unless outside funds are found quickly seems likely to produce results. Britain and the United States have agreed to accept a proposal, put by Professor Vic Hopper of Melbourne University during recent visits to both countries, to share running costs between the five principal users and to update some of the out-dated equipment.

The new proposal appeals to Britain in particular because the cost would be shared by more countries, Germany and Japan having become regular users of the facilities over the past four years. The plan would also allow user countries to up-date equipment by providing their own. Hence the United States and Germany might consider providing a better launch truck for heavier balloons and Britain would be willing to provide an improved kilobit telemetry link from its now abandoned Skylark rocket programme. Professor Hopper left for Germany and Japan last week to discuss his ideas there.

Britain seems to have come round to the view that it can hardly refuse Professor Hopper's proposal, especially if the United States, Germany and Japan also agree to cooperate. Compared to the cost of other collaborative projects with Australia, such as the Anglo-Australian telescope, the cost would be almost insignificant. In the interests of international collaboration, at least, it would probably be worth it.

Judy Redfearn

\section{Nuclear reactors}

\section{Czech closure}

In a sudden policy about-face, the Czechoslovak Nuclear Energy Commission has admitted that the country's first nuclear power station at Jaslovske Bohunice had to be closed down permanently after a major incident a few years ago. Speaking on Prague Radio, Milos Drahny, a senior official of the Commission admitted that a serious defect had damaged the 440-MW No. 1 generating set at the country's first VVER-440 light-water nuclear power station.

This admission follows almost two years of semi-official denials backed up by glowing accounts in the media of the benefits which the station was bringing to the Czechoslovak national economy (a claimed 2 million MW generated in 1979). As recently as 17 July 1980, Prague TV carried a news item reporting the completion of "summer maintenance work" on the No. 1 set.
The closure of the station was first reported in November 1978 in Document 22 of the Charter 77 movement. This document reported two accidents. The first, on 5 January 1976, was due to an obstruction in the safety valve of a fuel cell (probably due to human error), leading to an escape of radioactive coolant $\left(\mathrm{CO}_{2}\right)$ and the death of two workers who could not be evacuated in time, since one of the emergency exits had been locked as part of an anti-pilfering campaign. The second accident, on 24 February 1977, was due to human error in the loading of a fuel cell, producing a rupture in the primary circuit and extensive contamination in the primary and secondary circuits. Activated steam was voided into the atmosphere, and there was an escape of liquid into a nearby stream, which had to be fenced off temporarily.

The public discussion which the Chartists had hoped to evoke never materialized. The authorities took the stance that there was no accident. But the total absence of sound data (workers at the plant who had been at risk in the first accident were not even allowed to know the extra dosage they had absorbed) caused rumours to proliferate. By 1979 , it was widely believed that the liquid spilled from the second accident had got as far as the Danube - an allegation which the Chartists themselves have never either supported or denied, and which on the face of it would be very difficult to substantiate since the Danube Commission deals only with pollution caused by ships and there is, to date, no overall monitoring system for the river.

Document 22 in its concluding paragraphs called for a moratorium in the Czechoslovak nuclear energy programme until the public had been informed of, and had had a chance to consider, the hazards involved. But with the authorities firmly committed, like all Comecon countries, to nuclear power, construction went on apace; the No. 2 set at Jaslovske Bohunice is now undergoing acceptance trials, the Dukovany station is under construction and work on the Mochovce station has been started.

Nevertheless, and without any reference to Document 22, the Czech and Slovak media have from time to time appeared to be answering the Chartists on specific issues. One of the main criticisms made in Document 22 was of the psychological and physical health of the staff at Jaslovske Bohunice. The majority of workers, said the Chartists, were willing to work dangerously long hours without proper safety precautions in return for high pay and consoling themselves with alcohol and petty pilfering. Official releases countered this with descriptions of health and safety regulations, and the careful psychological monitoring of prospective employees. Other articles stressed safety precautions and contingency plans for antipollution measures in the event of any serious radiation leaks.

Drahny's belated announcement that such an accident has, in fact, already occurred, will come as no great surprise to the Czechs and Slovaks, accustomed as they are to the rewriting of the past. They may be intrigued, however, by the timing of the announcement, which came a few days before the anniversary of the 1968 Soviet intervention.

Vera Rich

\section{Space telescope}

\section{Edinburgh's bid}

Britain's Science Research Council (SRC) is to put in a bid to the European Space Agency (ESA) to house the European space telescope coordinating facility at the Royal Observatory, Edinburgh. Bids are also expected from the European Southern Observatory at Garching, West Germany, at least one astronomical institute in France and possibly one each in Spain and Italy. ESA plans to decide on a site early next year.

European scientists will receive at least 15 per cent of observing time on the space telescope - a joint ESA-US National Aeronautics and Space Administration (NASA) project - due for launch aboard the space shuttle in late 1983 , roughly in proportion to ESA's contribution to its capital cost. The task of the European Coordinating Facility (ECF) will be to receive data from NASA's Space Telescope Science Institute, and to analyse and disseminate them to European users of the space telescope, within a matter of days of receipt of the data in the United States. But bigger plans are afoot for the ECF. It will be designed to handle all data produced by the space telescope; ESA is currently negotiating with NASA to receive data

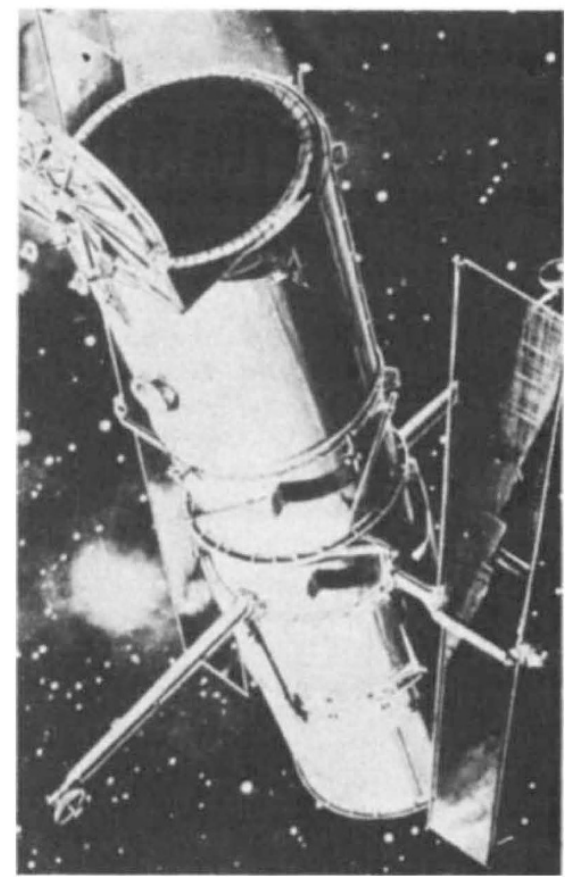

The space telescope - as it will look 